\title{
A Study on Interaction Design Studio Teaching
}

\author{
Gaosheng Luo \\ Xinyu University \\ Xinyu, China \\ e-mail: luo95@qq.com
}

\begin{abstract}
This paper is based on the current problems existing in the interaction design teaching. It describes the significance of interaction design studio teaching and discusses the construction of it from five aspects: the platform of schoolenterprise cooperation, studio set, project team, project curriculum and teaching management. It is hoped that this paper may provide some insights for the development of interaction design studio teaching in China.
\end{abstract}

\section{Keywords—interaction design; studio teaching; study}

\section{CURRENT PRoBlems IN INTERACTION DESIGN TEACHING}

With the development of Internet technology and the popularization of computers, novel artifacts emerge constantly with an increasing number of functions, while the cognitive friction between clients and novel artifacts is intensifying generally. Against this background, each massive emerging area and Internet enterprises pay more and more attention to customer satisfaction and retention, it is imperative that we should learn from the excellent cases both at home and abroad and learn how to cultivate talents suitable for China's reality in interaction designing so as to meet the practical needs and to meet the international standards. At present, majors of art design of many colleges and universities in China have started to study interaction design teaching. However, due to the practical situation of majors of art design in colleges and universities, interaction design teaching is faced with a lot of problems in the daily teaching practice:

1. Because of the short history of studies on interaction design in China, many research institutes, colleges and universities have not set up any specialized agencies for it. It will be a large and systematic project to set up scientific curriculum and build the knowledge system of interaction design effectively, and there will also be difficulties..

2. The teachers of interaction design are limited in quantity, energy and teaching experience. In interaction design studios, the teachers can hardly ensure every student getting perfect instructions. Colleges and universities have not optimized the teaching resources and integrated them with interaction design properly. As a result, some teachers work with heavy load, while others are too idle to complete the basic teaching tasks required by schools.

3. Interaction design teaching in China is usually conducted in the same way with art education in which classroom teaching plays a leading role. The general teaching procedure is like this: teacher teaching $\rightarrow$ students learning $\rightarrow$ teacher giving assignments $\rightarrow$ teacher's guidance on the assignment. In this procedure, we can see students study in a passive way without any motive to take an active part in it so that many students are in lack of practical skills and ability, and their designs are lacking in originality and creativity.

4. In terms of the management of interaction design teaching, many colleges and universities mainly adopt closed-end teaching, which makes them lacking in professional design teaching and practical teaching. Meanwhile, the interaction design teaching in some colleges and universities caters to the needs of the market, so as a result, students' design works are lacking in perspectiveness. Sometimes the interaction design research can not go deeper because there is not enough relevance between the project and the teaching theory, which has a great influence on the implementation of the teaching syllabus. Besides, the contradiction between the teaching organizational form and other majors increases the difficulty of teaching management to some degree.

5. China's school-enterprise cooperation policy didn't take effects as expected. In the cooperation, the enterprises' interests cannot be satisfied and there are not many activities in their cooperation with schools. The two sides hold different opinions about project cooperation, teaching arrangement, cooperation depth and value orientation; therefore, due to the contradictions, the cooperation between schools and enterprises is not effective enough.

\section{THE SigNifiCANCE OF INTERACTION DESIGN STUDIO TEACHING}

Compared with traditional teaching, interaction design studio teaching has made breakthroughs in many aspects. As for the construction of interaction design studio teaching, it is student-oriented and made up of some project teams, and the main teaching venue is the studio. Meanwhile, the teaching platform is open to particular students, which is benefit for the improvement of students' creativity, adaptability and the ability to operate in practice. The significance of interaction design studio teaching will be discussed from the following aspects:

1. Interaction design studio teaching can promote the cultivation of students' capability. In teaching activities, 
interaction design studio teaching emphasizes studentoriented learning and students' initiatives in the course of learning, and it can also enhance the interaction between students and teachers. It attaches great importance to team work among students, encouraging students to work together during interactive learning. When participating in some project activities, students are required to pay special attention to the cooperation among group members. If someone encounters problems or feels confused, he can turn to others for help without worrying about the experiment. This strengthens students' communicative ability, selfconfidence and teamwork awareness. In this way, instead of just receiving knowledge and messages passively, students start learning from the activities in various ways. They can have two-way communication with teachers and have more communication and cooperation with other students. Students can also improve their comprehensive abilities in the process of interactive learning in which they communicate and cooperate with each other and learn from each other. This teaching model enables teachers to instruct students in practice and students can also learn by practicing. Students keep innovating and put what they have learned into practice, which helps them improve their practical abilities.

2. Interaction design studio teaching help to promote teachers' professional teaching abilities. Interaction design studio teaching is more demanding so that teachers should develop their own professional abilities in the course of teaching students in the practical activities. More and more teachers are enriching their knowledge and improving their capability in order to meet the practical requirements of project teaching.

3. Interaction design studio teaching can enrich the connotation of the discipline of art design. As interaction studio teaching is acknowledged by more and more schools, enterprises and designers, this kind of teaching model gains popularization in teaching other designing subjects gradually, making interaction design education draw a large quantity of knowledge and ideas from various subjects and related areas. As a result, the discipline of art design maintains its exuberant vitality and keeps enlarging its connotation while striding in its initial direction.

4. Interaction design studio teaching can help to achieve a win-win situation between enterprises and schools. The practical projects of enterprises are the carrier of interaction design studio teaching. They help to foster students' comprehensive designing skills, which will meet the enterprises' needs in interaction designing talents. Interaction design proves to enterprises its value in the market and shows them the necessity of joining school teaching. Enterprises invest human and material resources properly in interaction design studio teaching so that the win-win situation between schools and enterprises can be achieved.

\section{CONSTRUCTION OF INTERACTION DESIGN STUDIO TEACHING}

\section{A. Construction of school-enterprise cooperation platform}

School-enterprise cooperation can be conducted in many ways, approaches and forms. As for which scheme to choose, enterprises and schools need to collaborate together according to practical situations. Schools and enterprises can adopt many ways such as regime and contract to achieve the goal of cooperation and co-management. Schools and enterprises can set up "Interaction design teaching construction group" and "Leading group for interaction design teaching reform and innovation" to build up the management system of the studio. Schools and enterprises ought to make an overall plan on the introduction of the project, establishment of the studio, deployment of the teaching staff, curriculum and so on. Schools and enterprises can also invite teams of specialists to authenticate the cooperation platform. The plan is shown in "Fig. 1".

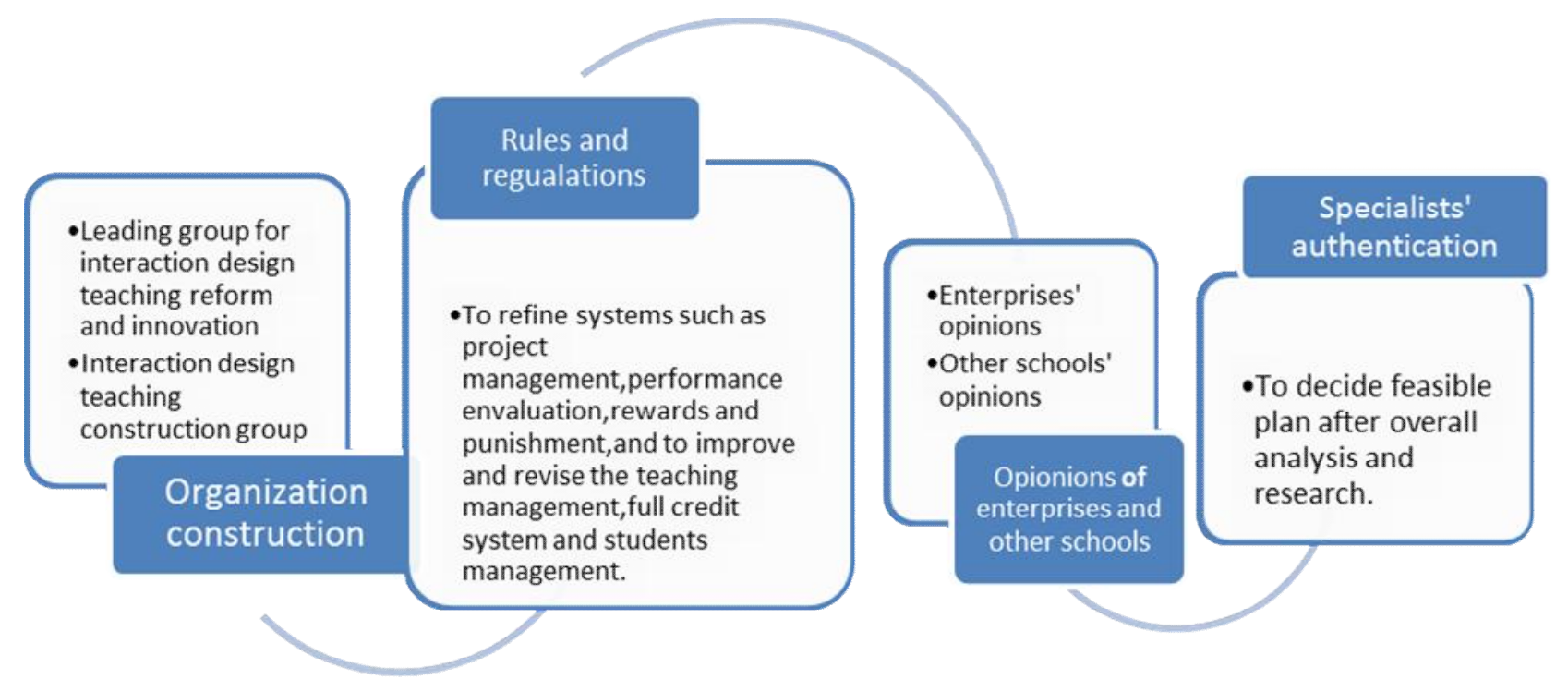

Fig. 1. . 


\section{B. Setting of interaction design studio}

The overall idea of interaction design studio teaching should depend on the setting of the studio. At present, more and more attention are paid to collective wisdom, communication and integrative thinking. Therefore reasonable and effective setting of functional area can help to show the time features of the studio construction. The setting of the functional zones can satisfy the realistic demands of interaction design studio, and it is also one of the significant links. Interaction design studio consists of working section, data section, client reception section, teaching section, demonstration section, discussion section, exhibition section, design section and so on. A certain amount of softwares and hardwares should to be equipped in each section. For example, materials and books should be equipped in the data section to facilitate students' research work; in the design section there is software equipment for computers; and the teaching section is equipped with blackboard, desks and chairs, multimedia curtains and platforms as shown in "Fig.2".

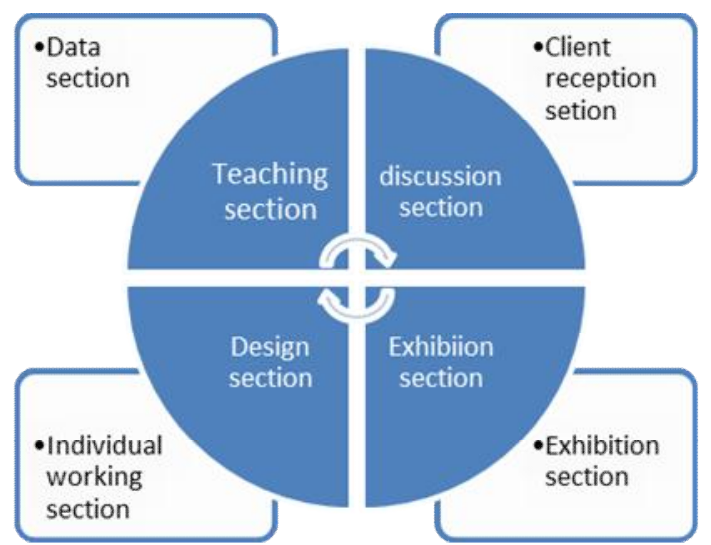

Fig. 2.

\section{Establishment of the open project team}

Based on the criteria of openness, colleges and universities need to set up open project teams focusing on project activities. Both teachers and students can set up their project team according to their own hobbies and specialties. Part-time specialists employed from outside the school, interaction design teachers and teachers of other majors can act as the leaders of the project teams. Thanks to the cooperation with enterprises, colleges and universities can employ very experienced interaction design engineers and designers from enterprises to build an interaction design teaching team where professional and part-time teachers can work together. Interaction design studio needs to build all kinds of open teams for the studio among all the teachers and students regardless of their grade and class. Each team consists of 8 to 12 students one of whom will be the group leader. The leader should be elected by all the other students judging from his or her professional level, working attitude and sense of responsibility as shown in "Fig. 3".

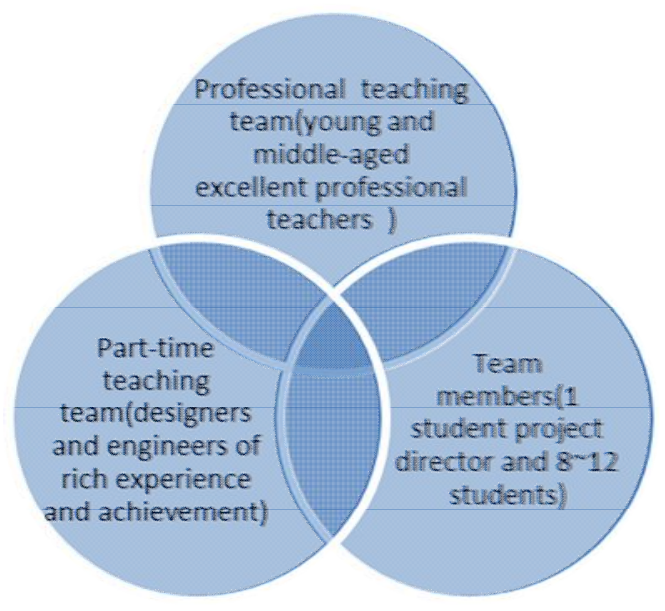

Fig. 3.

\section{The circular progress of project curriculum}

According to the teaching plan of interaction design studio, students can respectively choose their project courses (both on virtual topics and realistic topics). In general, every project course has one or several designing tasks. In the design of the project curriculum, schools and enterprises have to break the limitation of "chapter" in the test book and adopt circular progressive project teaching model as shown in figure 4. For example, sample designing, logo designing and poster designing courses can be carried out through different projects, while courses that are related can be combined into an integrated project in the studio, such as brand marketing and advertising plan and the like. When choosing a project course, schools and enterprises should make choices according to the practical situation instead of setting up courses without discrimination. Schools and enterprises ought to select according to industrial characteristics and project difficulty. The selection of courses should be based on the understanding of interaction design features so that in the process of completing projects, students can learn some useful theories and practical skills. Let's take the 2D design teaching in the Design School of Wuhan University of Technology as an example. The design of a DVD disk should contain design of the cover, instruction and related interface among which the design of interface is the core. Therefore, this project is closely related to culture, technology, art and so on, and the participants can learn abundant knowledge during the process. When the social projects are put into the practical activities of interaction design studio, students should be encouraged to take an active part in various design competitions held by schools, universities, provinces, the nation and the studio itself so that they can bring their design into a more advanced level. 


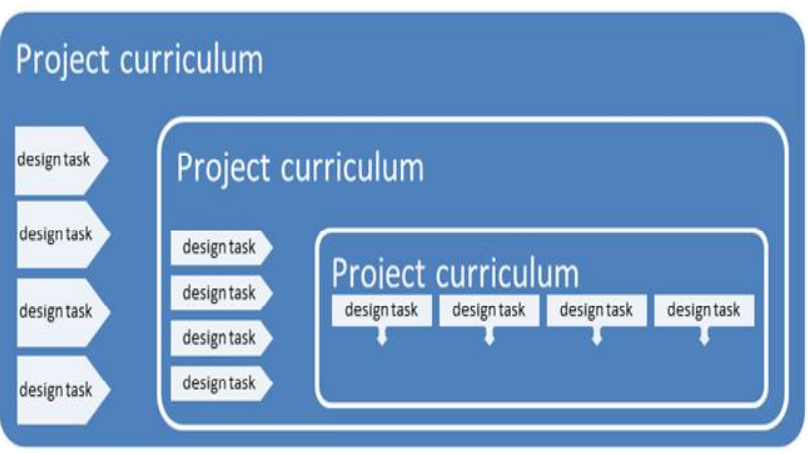

Fig. 4.

\section{E. The management of interaction design studio teaching}

All the students have the opportunity to get access to interaction design studio to study, but,they have to achieve the standards of prerequisite courses in the interaction design studio. It will be a two-way selection process because students are entitled to register for the project courses of the studio, and schools and enterprises also have the right to select from the applicants. Project director communicates with the clients and coordinates team works. Under the teachers' guidance, students can join in teaching activities in person including the consultation of projects, designing and selection of schemes, project implementation and so on. Every student has his or her own role and their tasks are different from one another. The way they act has an influence on the process and outcome of the project. Therefore, students can know their specialties better and realize their personal value through project courses by playing their different roles. Their professional capabilities get improved in practice and their sense of responsibility enhances. In the process of studio teaching, project courses have connected learning records and time settings to ensure the accomplishment of the project and achieve the expected learning effect. After taking the project courses, students should make a summary of their studies and practice in the studio. They should realize their advantages and disadvantages in practice, learn from their experience and make progress constantly in order to play an active part in practical activities. Moreover, students need to record the process of their practice on paper or disk and hand the recording in to the dean's office for registration. Meanwhile, they need to deliver reports to exhibit their achievements. Teachers need to explain and comment on students' works as well as periodical works. When the design works are put into use in the market, market has an absolute say for the quality of the works. Teachers should give relevant guidance according to the needs of the market to improve the quality of the works. Teachers should also calculate and analyze the exhibitions in the studio and make a summary of their teaching experience so as to improve the quality of interaction design studio teaching.

\section{REFERENCES}

[1] Yu Wei-zhong, "Thinking and Exploration of the Practice Teaching Model for Majors of Art Design in Vocational College," Research and Exploration in Laboratory, Vol.28, No.2, 2009.

[2] Feng Yong-hui, "Discussion on the Workshop Teaching of Unity of Art and Technology", Art Observation, No.10,2009.

[3] Luo Gao-sheng, "Thinking of 'Studies, Grinds, Unifies_-Unifies, Studies, Grinds' Teaching Pattern-Taking Art Design Project Workshop of Xinyu University as An Example”, Design, No.2, 2013.

[4] Wang Wei-ding, "Study of Teaching Mode of Tutor's Workshop System of Visual Transmission Design," Packaging Engineering, Vol.30, No.8,2009.

[5] Sun Lian-dong, Yang Wei-qun, Liu Yu-jie, “ Discussion of the Construction of Workshop Based on the Integration of Work and Study," Staff Forum, No.11,2010.

[6] Ye Guo-feng, "Construction of Teaching Platform of 'Studio System' and Development of Creative 'High-Skill' Talents," Journal of Zhejiang Vocational Academy of Art, Vol.8, No.2, 2010.

[7] Liu Hong-bo, "On the Function Design and Environment Construction of Creative Studio for Art Design Major in Higher Vocational Colleges," Art Panorama, No.12,2010.

[8] Luo Gao-sheng, "On the Practice of Project Studio Teaching Mode in Art Design Major,” Journal of Xinyu University, Vol.18, No.1, 2013. 